\title{
LITERATURA AFRO-BRASILEIRA ROMPENDO BARREIRAS ATRAVÉS DA TRADUÇÃO: ALGUMAS CONSIDERAÇÕES SOBRE A RECEPÇÃO DE PONCIÁ VICÊNCIO NA FRANÇA
}

\section{AFRO-BRAZILIAN LITERATURE BREAKING BARRIERS THROUGH TRANSLATION: SOME THOUGHTS ABOUT THE RECEPTION OF PONCIÁ VICÊNCIO IN FRANCE}

\author{
Marcela lochem Valente \\ Teresa Dias Carneiro
}

\section{RESUMO}

O romance Ponciá Vicêncio, da escritora afro-brasileira Conceição Evaristo, publicado em 2003 pela editora Mazza, foi traduzido para o inglês pela editora estadunidense Host, em 2007 e, recentemente, em 2015, no Salão do Livro em Paris, ganhou vida também em francês, através da editora Anacaona que lançou L'bistoire de Poncia, com tradução de Patrick Louis e Paula Anacaona. É interessante o fato de que a obra de uma escritora não muito conhecida no Brasil tenha sido selecionada para ser traduzida para duas línguas, até o momento. Assim, o presente artigo objetiva trazer algumas considerações sobre a recepção de L'bistoire de Poncia na França, investigando alguns aspectos sobre a acolhida da obra em tal contexto.

Palavras-chave: literatura afro-brasileira; tradução; recepção.

\section{ABSTRACT}

The novel Ponciá Vicêncio, by the Afro-Brazilian writer Conceição Evaristo, published in 2003 by Mazza publisher, was translated into English by Host Publications in 2007 and, recently, in 2015, in the Paris Book Fair, it was also launched in French, by Anacaona publisher, as L'bistoire de Poncia, translated by Patrick Louis and Paula Anacaona. It is interesting to notice the fact that the work of a largely unknown writer in Brazil has been selected to be translated into two languages so far. Thus, this article aims to bring some thoughts about the reception of L'bistoire de Poncia in France, investigating some aspects of the reception of the novel in such context.

Keywords: afro-Brazilian literature; translation; reception.

\footnotetext{
* Universidade do Estado do Rio de Janeiro, Rio de Janeiro RJ. Brasil. marcellaiv@ig.com.br ** Universidade Federal do Rio de Janeiro, Rio de Janeiro RJ. Brasil. teresadc@terra.com.br 


\section{INTRODUÇÃO}

A escritora afro-brasileira Conceição Evaristo teve o seu primeiro romance Ponciá Vicêncio publicado em 2003 pela editora mineira Mazza, uma editora de pequeno porte interessada em literatura afro-brasileira. Segundo relatos de Maria Mazarello Rodrigues, dona da editora, através de troca de e-mails com Marcela Iochem Valente em 2013, o romance teve, inicialmente, uma tiragem experimental de mil exemplares em parceria com a escritora que custeou parte da publicação, e, posteriormente, uma edição especial custeada pela editora com tiragem de cinco mil exemplares e reimpressão de dez mil exemplares por conta das indicações do livro como leitura obrigatória para vestibulares de instituições mineiras como a UFMG, o CEFET Minas, entre outras. Embora cerca de dezesseis mil exemplares do romance tenham sido vendidos no Brasil, a escritora Conceição Evaristo e sua obra ainda não são muito conhecidas do público brasileiro. Dentro da própria academia, na área de Letras, a escritora e sua obra possuem pouca visibilidade e circulam apenas em contextos bastante restritos, ganhando espaço, geralmente, em discussões relacionadas às questões de gênero e etnia. Por essa razão, acreditamos ser de grande relevância o fato de que um romance de circulação restrita em seu país de origem, publicado por uma pequena editora e pouco conhecido do público geral tenha sido selecionado por editoras estrangeiras para que pudesse ser traduzido para as línguas inglesa e francesa.

Embora o presente artigo vá se ocupar da tradução do romance Ponciá Vicêncio para a língua francesa, cabe mencionar, mesmo que de forma breve, a sua tradução para a língua inglesa. Ponciá Vicêncio foi publicado nos Estados Unidos pela editora Host em 2007, com tradução de Paloma Martinez-Cruz, professora assistente de Estudos de Cultura e Literatura Latina, do Departamento de Espanhol e Português, da Ohio State University. Em entrevista a Valente, publicada na tese de doutorado A tradução e a construção de imagens culturais: Ponciá Vicêncio, de Conceição Evaristo, e sua tradução para o inglês (2013), um diretor da Host afirma que dada a surpreendente procura pela obra de Evaristo nos Estados Unidos, contexto não muito receptivo à literatura estrangeira traduzida, a editora produziu uma reimpressão da obra, incluindo até mesmo, alguns exemplares em capa dura (VALENTE, 2013, p.146). Por conta da publicação do romance em língua inglesa, Evaristo teve a oportunidade de proferir palestras em inúmeras universidades estadunidenses e sua obra vem sendo cada vez mais estudada em tal país. Mais detalhes sobre a tradução e a recepção do romance no contexto estadunidense podem ser encontrados em estudos como Valente (2013), Silva e Valente(2014). 
Recentemente, no Salão do Livro de Paris, em março de 2015, foi lançada a tradução do romance em questão para a língua francesa, pela editora Anacaona. L'bistoire de Poncia foi traduzido por Patrick Louis e Paula Anacaona, tradutora e dona da editora que publicou a tradução. A editora Anacaona é interessada em literatura não canônica e não divulgada por grandes editoras, principalmente aquelas provenientes da periferia. Segundo a tradutora, em entrevista concedida ao Jornal do Commercio online, a editora surgiu de "um pequeno projeto de levar obras alternativas às livrarias do seu país" (GUEDES, 2015, s.n.p.). Anacaona afirma: "[n]ão achei que ia ficar rica, claro, mas vi que havia uma lacuna, com muitos livros bons que não eram traduzidos. Na França não se falava nada da literatura marginal e nem se tinha aqui um movimento parecido" (GUEDES 2015, s.n.p.). O catálogo da editora Anacaona inclui obras de escritores como Ferréz, Eliane Brum, Ana Paula Maia, Marcelino Freire, Marçal Aquino, João Luiz Carrascoza, Rachel de Queiroz, José Lins do Rego, em sua grande maioria selecionadas e traduzidas pela própria Paula Anacaona: "Como editora, queria mostrar que é possível trazer diversidade e, como tradutora, queria trabalhar ao mesmo tempo com nomes como Ferréz e José Lins do Rêgo" (ANACAONA apud GUEDES 2015, s.n.p.). Paula Anacaona destaca ainda o papel político e social da literatura, que pode romper barreiras nacionais através da tradução, e aponta alguns aspectos que ela considera convergentes entre os contextos brasileiro e francófono:

Há contatos entre as periferias da França e do Brasil. O sentimento de exclusão é igual em todo o mundo, por mais que as reações às vezes sejam diferentes. A luta que a literatura marginal brasileira faz para que jovens não entrem no tráfico de drogas, aqui pode ser para que eles não entrem em guerras santas, o que está acontecendo muito. (ANACAONA apud CASARIN, 2015, s.n.p.)

Nesse contexto, produções literárias como a de Conceição Evaristo vão muito além da estética e da qualidade literária, podendo suscitar importantes discussões e até mesmo ter um papel de grande relevância em mudanças sociais.

O presente artigo tem como objetivo investigar alguns aspectos sobre a recepção de L'bistoire de Poncia na França, trazendo algumas considerações sobre a acolhida da obra em tal contexto, embora a tradução em questão seja ainda bastante recente.

\section{BREVES CONSIDERAÇÕES SOBRE A ESCREVIVÊNCIA AFROFEMININA DE CONCEIÇÃO EVARISTO}

A escritora Conceição Evaristo nasceu em Belo Horizonte em 1946 em uma família bastante humilde e, por essa razão, precisou trabalhar desde muito jovem nos 
afazeres domésticos para que pudesse ajudar a sua família. Mesmo em um cenário de pobreza e dificuldades, Evaristo aprendeu a ler, teve acesso à educação formal, fez curso normal ainda em sua cidade e, anos mais tarde, após sua mudança para o Rio de Janeiro, ingressou no curso de Letras, na Universidade Federal do Rio de Janeiro, no mestrado em Literatura Brasileira na Pontifícia Universidade Católica do Rio de Janeiro, e no doutorado em Literatura Comparada na Universidade Federal Fluminense.

A produção de Evaristo conta com poemas e contos publicados na série Cadernos Negros; com os romances Ponciá Vicêncio (2003) e Becos da Memória (2006); e com quatro coletâneas: Poemas da recordação e outros movimentos (2008) - coletânea de poemas, Insubmissas lágrimas de mulheres (2011), Olhos d'água (2015) e Histórias de leves enganos e parecenças (2016) - coletâneas de contos. Além disso, a escritora também publica trabalhos acadêmicos, ensaios, apresenta inúmeras falas e palestras no Brasil e no exterior e ainda conta com o blog "Nossa Escrevivência", hospedado em http://nossaescrevivencia.blogspot.com.br/, lançado pela escritora em novembro de 2012, onde está disponível, além de sua tese de doutorado, "informações sobre os livros já publicados por Evaristo, textos da escritora, entrevistas, depoimentos, vídeos, artigos publicados sobre sua obra e material sobre a literatura afro-brasileira de um modo mais amplo" (VALENTE, 2013, p. 11). Ao elencarmos sua produção, não podemos deixar de citar ainda Ponciá Vicencio ${ }^{4}$ (2007) e L'bistoire de Poncia (2015), as traduções de seu primeiro romance para as línguas inglesa e francesa, respectivamente.

Ponciá Vicêncio nos apresenta a trajetória da protagonista homônima, desde sua infância até a idade adulta, mostrando seu processo de migração do campo para a cidade grande e seu posterior retorno à sua terra de origem. Ponciá é uma mulher negra, descendente de escravos, que enfrenta momentos de grandes perdas familiares durante sua vida: pai e avô falecidos, mãe e irmão desaparecidos, sete filhos perdidos. Seus avós experienciaram a escravidão e seus pais, embora beneficiados pela Lei do Ventre Livre, ainda vivem sob os resquícios dessa escravidão, em uma pseudoliberdade, nas terras de seus antigos donos. Coronel Vicêncio alegava que as terras eram um "presente de libertação. (...) Uma condição havia, entretanto, a de que continuassem todos a trabalhar nas terras" (EVARISTO, 2006, p.48). Assim, a menina e sua mãe Maria Vicêncio produzem utensílios de barro que vendem nas proximidades da Vila Vicêncio para ajudar no sustento da família, e cuidam dos

1. Embora o nome da protagonista tenha sido mantido como título da tradução para a língua inglesa, tal qual acontece no romance em sua língua de partida, em inglês, houve uma adaptação ortográfica e o acento circunflexo de "Vicêncio" foi retirado. 
afazeres domésticos, enquanto seu pai e irmão trabalham na lavoura, terras do Coronel Vicêncio, ficando dias longe de casa e de sua família. Já adulta, após a morte repentina de seu pai e insatisfeita com a vida ainda escrava que levava, mesmo vivendo em um período pós-abolicionista, Ponciá decide buscar uma vida melhor para si na cidade grande, onde, após dificuldades iniciais, consegue um emprego como empregada doméstica. A vida na cidade não se mostra fácil e, apenas muitos anos após a sua chegada, Ponciá consegue comprar um quartinho em um morro na periferia da cidade, voltando em seguida ao seu povoado de origem em busca de sua mãe e irmão, porém, deparando-se com a casa vazia. Em momentos e situações diferentes, ambos, mãe e irmão, partem para a cidade na esperança de encontrarem uns aos outros, entretanto a história é repleta de desencontros. Por fim, na estação de trem da cidade, após idas e vindas, sofrimentos e desencontros, a família se reencontra e retorna ao campo após perceberem que a cidade não oferece a vida melhor que todos buscavam. Ponciá percebe que, mesmo ali, na tão sonhada cidade grande, ainda vive a vida escrava da qual tentava se libertar: "[e]scrava de uma condição de vida que se repetia. Escrava do desespero, da falta de esperança, da impossibilidade de travar novas batalhas, de organizar novos quilombos, de inventar outra e nova vida" (EVARISTO, 2006, p.83).

Embora tenhamos apresentado o enredo em linhas muito gerais, é marcante, ao longo de todo o romance, os questionamentos que Ponciá apresenta em relação à vida que levava com sua família no campo e ainda à vida que leva ao se mudar para a cidade grande. A protagonista se mostra, todo o tempo, insatisfeita com as condições em que vive, pois, se sua família já não é mais escrava, por que vivem ainda nas terras do Coronel Vicêncio? Se são beneficiados pelas leis Áurea e do Ventre Livre, por que precisam viver uma vida escrava, em condições degradantes? Se não é mais escrava, por que ainda sofre com as condições de uma nova escravidão que encontra na cidade grande para onde se muda em busca de uma vida melhor?

Os negros eram donos da miséria, da fome, do sofrimento, da revolta suicida. Alguns saiam da roça, fugiam para a cidade, com a vida a se fartar de miséria, e com o coração a sobrar de esperança. Ela mesma havia chegado à cidade com o coração crente em sucessos e eis no que deu. Um barraco no morro. Um ir e vir para a casa de patroas. Umas sobras de roupa e de alimento para compensar um salário que não bastava. (EVARISTO, 2006, p.82)

O romance de Evaristo narra problemas do cotidiano das mulheres negras e da pobreza, de forma muito rica e cheia de referências culturais, partindo de uma ótica feminina e afrodescendente. Sua obra lança luz sobre um grupo historicamente excluído no Brasil e questiona os cânones brasileiros, que tendem a priorizar obras produzidas pelas supostas maiorias ou, ainda, pelos membros da dita sociedade 
hegemônica, tida como padrão. A publicação e a tradução de obras como Ponciá Vicêncio não apenas dá voz a esses grupos deixados à margem de nossa sociedade, mas ainda permite que partes da cultura brasileira, por muito tempo encobertas, possam ser conhecidas internacionalmente, dando alguma visibilidade a grupos que a história por muito tempo excluiu ou apresentou de maneira estereotipada, conveniente aos relatos hegemônicos.

Embora, segundo a autora, Ponciá não seja um texto autobiográfico, Evaristo utiliza a trajetória da protagonista de seu primeiro romance, para ressaltar várias das dificuldades que ela mesma, enquanto mulher e negra vivendo no Brasil, enfrentou ao longo de sua adolescência e idade adulta. Sua escrevivência afrofeminina inclui aspectos como a dificuldade para encontrar seu espaço na sociedade, ter um emprego e crescer profissionalmente, questões enfrentadas, embora de maneiras muito diferentes, por ambas, Ponciá Vicêncio e sua criadora. "Tendo sido exposta desde pequena às crueldades do racismo, Conceição tornou-se uma escritora negra de projeção internacional, além de uma militante que atua dentro e fora dos marcos da academia" (ARAÚJO, 2011, s.n.p.). Através de sua escrita engajada, Evaristo busca revelar a desigualdade velada de nossa sociedade, escondida atrás do manto do Mito da Democracia Racial, revelando o histórico de opressão e exclusão enfrentado pelo povo negro brasileiro ao longo de nossa história.

Obras como Ponciá Vicêncio, de Conceição Evaristo, são a prova de que é possível se fazer emergir uma literatura daqueles autores que os livros didáticos ocultam, reafirmando uma História que sempre os omitiu e os embranqueceu. Uma Literatura que os renegou e trouxe os personagens negros encaixados em estereótipos e, na maioria das vezes, mudos e desprovidos, inclusive, do olhar. (ARRUDA, 2007, p. 93)

No Brasil, Evaristo ainda não alcançou visibilidade e reconhecimento de mérito, sendo uma escritora desconhecida da maioria e com sua obra vendida apenas em contextos muito específicos, geralmente, em livrarias especializadas. Em contrapartida, sua obra vem sendo cada vez mais pesquisada e é bastante comum encontrarmos um número muito expressivo de trabalhos sobre Evaristo, seus poemas, contos e romances em congressos e eventos em geral da área de Letras, que contemplem os estudos de gênero e etnia. Porém, embora Evaristo seja a segunda escritora afro-brasileira traduzida para outras línguas, sendo Carolina Maria de Jesus a primeira, e embora sua obra seja recebida de forma extremamente positiva pelos acadêmicos da área de Letras que se ocupam de questões como negritude e feminismo, sua obra ainda possui grande dificuldade de circulação, o que provavelmente contribui bastante para que a escritora ainda não seja conhecida pelo público brasileiro de modo mais amplo. Como questiona Bárbara Araújo (2011) 
[u]ma das mais importantes escritoras negras da atualidade não figura nas prateleiras das grandes livrarias no país, tampouco nos grandes manuais de literatura brasileira. Por que será? $\mathrm{O}$ que tem a obra de Conceição que a impede de circular amplamente, apesar do prestígio que ela obteve nos meios especializados, nos meios "negros"? (ARAÚJO, 2011, s.n.p.)

Acreditamos que tal pergunta esteja respondida, em parte, no presente artigo, ao discutirmos a escrevivência afrofeminina de Evaristo, que quebra silêncios e questiona cânones, estereótipos e histórias, assumindo um forte caráter político e ideológico.

Mesmo com toda a dificuldade de circulação que a obra de Evaristo encontra no Brasil, sua obra vem sendo lida e estudada em seu país de origem, e o interesse por Evaristo e sua produção literária está rompendo barreiras nacionais através de suas traduções. Nos últimos anos, é notável que, cada dia mais, Evaristo venha ganhando visibilidade em outros países. Nos Estados Unidos a sua obra vem sendo bastante estudada e a escritora tem se tornado tema de inúmeros trabalhos. Além disso, Evaristo tem recebido diversos convites para proferir palestras no exterior em eventos como: a $7^{\text {th }}$ International Caribbean Women Writers and Scholars Conference, em Porto Rico; eventos nas universidades de Yale, Columbia, Tenessee, Brown e Iowa nos Estados Unidos; a X Feira Internacional do Livro em Havana, Cuba; o Salão do Livro, em Paris, apenas para mencionar alguns. E é nesse contexto que acreditamos ser muito relevante investigar como a mais recente tradução de seu romance Ponciá Vicêncio está sendo recebida na França desde o seu lançamento no Salão do Livro de Paris.

\section{L'HISTOIRE DE PONCIA: LITERATURA AFRO-BRASILEIRA, NÃO CANÔNICA, NA FRANÇA}

Até a realização do Salão Internacional do Livro de Paris, que aconteceu em março de 2015, pouco se ouvia falar sobre a tradução do romance de Conceição Evaristo para a língua francesa. Em buscas na internet e outras mídias, conseguia-se ter acesso apenas à informação de que o Brasil seria o convidado especial do evento e que a escritora estaria compondo a delegação de autores brasileiros que foram selecionados para participar do evento representando o nosso país. Nesse primeiro momento não havia, sequer, menção à editora que estaria traduzindo a sua obra e nem estava claro qual seria a obra traduzida. Porém, durante o evento, o quase anonimato em relação à publicação do romance de Evaristo em francês, deu lugar a matérias e notas sobre a surpreendente acolhida de sua publicação: "[e]la é um dos nomes brasileiros mais assediados até agora no salão. Depois de falar numa mesa, no 
sábado, deu autógrafos, tirou fotos e conversou com leitores por quase uma hora" (NEVES, 2015, s.n.p.).

A própria escritora Conceição Evaristo afirma que foi surpreendida com o grande assédio no Salão Internacional do Livro de Paris e com o reconhecimento que teve por conta de seu romance Ponciá Vicêncio. Em entrevista ao jornal Folha de São Paulo em 23 de março de 2015, Evaristo afirma que

[seu] caso chama a atenção porque não é muito comum uma escritora brasileira negra participar de uma feira internacional. A gente fica como fruta rara. (...) a presença negra fora das instâncias em que se está acostumado a vê-la causa furor (...) não seria a mesma coisa se isso aqui fosse um festival de gastronomia em que baianas estivessem preparando acarajés. (EVARISTO, apud NEVES, 2015, s.n.p.)

É interessante notar que a escritora evidencia o seu lugar de enunciação como uma escritora negra, brasileira, mulher, todo o tempo. Ela deixa claro em seu discurso o seu posicionamento engajado e a busca por voz e visibilidade para as questões raciais em nosso país.

No que diz respeito à recepção de L'histoire de Poncia, como a tradução francesa do romance foi publicada em março de 2015, ainda não há muito material disponível sobre a recepção crítica e geral do mesmo. Porém, em uma busca cuidadosa, além das inúmeras matérias publicadas em jornais e em diferentes fontes na internet por conta do Salão do livro de Paris, é possível termos acesso a algumas resenhas e algumas avaliações do romance em sites como o "Babelio", e o da própria editora "Anacaona" ${ }^{1}$, que reserva espaço para que o leitor comum poste sua avaliação. Acreditamos ser relevante falarmos sobre essas resenhas que aparecem na internet, pois tais espaços acabam funcionando como formadores de opinião, já que um possível leitor que decida fazer uma busca online antes de decidir pela leitura do livro facilmente terá acesso a essas avaliações.

Até o momento da conclusão da presente pesquisa (setembro de 2015), o leitor que buscar referências na web sobre L'Histoire de Poncia encontrará uma avaliação bastante positiva para a obra de Evaristo. No site "Babelio", o romance recebeu seis avaliações e, de cinco estrelas possíveis, foi avaliado com 3,83 estrelas, o que mostra uma recepção positiva por parte dos leitores. É interessante notar que mesmo nas duas avaliações em que o romance recebeu as suas menores notas, três estrelas, as resenhas são muito positivas. Uma resenha termina com um agradecimento à editora Anacaona por ter possibilitado a leitura do romance em francês "Un grand merci à Paula et aux éditions Anacaona pour ce voyage au coeur du Brésil et de la

2. http://www.babelio.com/livres/Evaristo-Lhistoire-de-Poncia/699424

3. http://www.anacaona.fr/boutique/1_histoire_de_poncia_conceicao_evaristo/ 
saudade $^{\prime \prime 4}$ (2015); e a outra termina ressaltando que o romance de Evaristo trata da história dos negros brasileiros, descendentes de escravos, que precisam conviver com o legado do passado de escravidão, temas tratados pela escritora de forma muito íntima e pessoal, com palavras que hipnotizam e emocionam, e que a leitora sequer suspeitava da existência antes da leitura de L'bistoire de Poncia:

\begin{abstract}
L'Histoire de Ponciá c'est l'histoire des Brésiliens noirs, descendants d'esclaves, qui ne savent que faire de cet héritage qu'ils n'ont pas choisi; qui, ne sachant comment être libres retournent inconsciemment à leurs fers et ne peuvent se défaire des legs du passé. Ce sont les enjeux socio-démographiques propres au Brésil qui sont ici abordés par laauteur de façon très personnelle et intime. Les mots de Conceiçao Evaristo nous hypnotisent, nous propulsent dans un monde et nous balancent des émotions dont on ne soupçonne même pas l>existence. Un roman sur limportance de ses racines et de son héritage qui touche bien au-delà de l>identité noire-brésilienne. A lire d`urgence! $(2015)^{5}$
\end{abstract}

É interessante que todas as resenhas apresentadas no site "Babelio" ressaltam a forma bela com que Evaristo tratou das questões raciais em nosso país, como podemos ver em uma outra resenha "[u]n magnifique petit roman qui évoque sobrement et avec beaucoup de poésie la discrimination raciale au Brésil, la migration des paysans vers les villes par la voix vibrante d'une femme en quête de son identité et de ses racines" ${ }^{\prime \prime}$ (2015).

No site da editora Anacaona o romance de Evaristo recebeu cinco avaliações. Delas, quatro leitores avaliaram o livro com cinco estrelas e um leitor avaliou L'Histoire de Poncia com quatro estrelas. Na primeira avaliação apresentada, em abril de 2015, o leitor Jean-Francis B afirma que o livro é apaixonante e maravilhoso e elogia ainda o prefácio, que é uma fala da escritora Conceição Evaristo traduzida para o francês: "Poncià est un livre PASSIONNANT ET MERVEILLEUX.... Le texte mis en préface est grandissime! Merci"7 (2015).

4. Agradeço muito a Paula e às edições Anacaona por essa viagem ao coração do Brasil e da saudade. [tradução das autoras]

5. L'Histoire de Ponciá é a história dos negros brasileiros, descendentes de escravos, que não sabem o que fazer com essa herança que não escolheram; que, não sabendo como ser livres voltam inconscientemente aos ferros e não conseguem se desfazer do legado do passado. São as questões sócio-demográficas do Brasil que são aqui abordadas pela autora de forma muito pessoal e íntima. As palavras de Conceição Evaristo nos hipnotizam, nos propulsionam em um mundo e mexem com emoções das quais nem se suspeitava a existência. Um romance sobre a importância de suas raízes e de sua herança, que toca bem além da identidade negra brasileira. Para se ler com urgência! [tradução das autoras].

6. [u]m magnífico pequeno romance que evoca com sobriedade e muita poesia a discriminação racial no Brasil, a migração dos camponeses para as cidades pela voz vibrante de uma mulher em busca de sua identidade e de suas raízes. [tradução das autoras]

7. Ponciá é um livro APAIXONANTE E MARAVILHOSO... O texto do prefácio é incrível! Obrigado. [tradução das autoras] 
Por fim, gostaríamos de considerar as avaliações e resenhas contidas no site da "Amazon" ${ }^{1}$, também grande formador de opiniões. O referido site traz o texto de apresentação do romance disponibilizado pela editora Anacaona, breves dados biográficos da autora, algumas informações técnicas sobre a publicação e a avaliação máxima para o livro, cinco estrelas. Na "Amazon", L'Histoire de Poncia recebeu apenas duas avaliações, porém ambas conferindo a nota máxima para o romance. A leitora Flora Figueiredo avalia o romance como uma bela descoberta da literatura brasileira, que traz, através de um ponto de vista feminino e de uma linguagem poética, memórias de um passado de escravidão:

L'histoire de Poncia c'est une belle découverte de la littérature brésilienne. Une histoire pleine d'une mémoire forte et poétique du peuple noir par le point de vu d'une femme. Poncia raconte des histoires de ses grands-parents esclaves et son quotidien dur parmi ses rêves d'une vie meilleure. Lecture recommandée à tous. (FIGUEIREDO, 2015, s.n.p.) ${ }^{9}$

A leitora Costa Céline, no mesmo site, também recomenda a leitura do livro, apontando o mesmo como uma leitura informativa, poética e comovente. Para Céline, o romance é uma viagem comovente ao passado, que mostra sonhos, esperanças e desesperos de Ponciá, em um processo de busca por identidade: "L'Histoire de Poncia est un voyage poignant dans le passé, les rêves, les espoirs et désespoirs de Poncia, petite fille d'esclave en quête d'identité. Lecture instructive, poétique et émouvante que je recommande"10 (CÉLINE, 2015, s.n.p.).

Percebe-se, tanto no site da FNAC quanto no site da Amazon.fr, que a apresentação do livro está baseada no material veiculado pela editora Anacaona. Pode-se inferir que os artigos críticos a serem escritos deverão também tomar por base este material de apresentação da editora. Nesse texto ${ }_{1}^{11}$ existem quatro chaves de leitura importantes: 1. a qualificação do romance como roman d'apprentissage (em português, "romance de aprendizagem"); 2. a inscrição do romance no catálogo da editora entre l'Enfant de la plantation et Je suis favela; 3. a comparação de Conceição Evaristo com Toni Morrison ("à l'image d'une Toni Morrison aux Etats-Unis, l'oeuvre de Conceição Evaristo est la parfaite illustration de la façon dont la

8. http://www.amazon.fr/L-histoire-Poncia-Conceicao-Evaristo/dp/2918799750

9. L'Histoire de Poncia é uma bela descoberta da literatura brasileira. Uma história cheia de uma memória forte e poética do povo negro pelo ponto de vista de uma mulher. Poncia conta estórias de seus avós escravos e de seu cotidiano difícil em meio a seus sonhos de uma vida melhor. [tradução das autoras]

10. L'Histoire de Poncia é uma viagem pungente ao passado, aos sonhos, aos desesperos de Poncia, neta de escravos em busca de sua identidade. Leitura instrutiva, poética e emocionante que recomendo. [tradução das autoras]

11. http://www.anacaona.fr/boutique/1_histoire_de_poncia_conceicao_evaristo/ 
littérature peut aider à mieux comprendre un pays et la lutte de tout un peuple pour sa reconnaissance...." $)^{12}$; 4. a informação de que o romance é leitura obrigatória no vestibular no Brasil e que vendeu cerca de vinte mil exemplares, tendo sido traduzido em inglês e espanhol.

$\mathrm{Na}$ teoria literária, o romance de aprendizagem designa o tipo de romance em que é exposto o processo de desenvolvimento físico, moral, psicológico, estético, social ou político de um personagem, desde a sua infância ou adolescência até a idade madura. Contudo, Denis Pernot ressalta que "o discurso crítico francês contemporâneo faz um emprego frequente, mas extremamente confuso das noções genéricas de 'romance de educação', 'romance de formação' e 'romance de aprendizagem'", intercambiando essas designações sem muito critério (PERNOT, 1994, p. 105). Essas denominações nascem do conceito alemão de Bildungsroman, que procura dar conta de um campo de aplicação culturalmente homogêneo (a Alemanha no século XVIII), mas, ao mesmo tempo, ultrapassa os limites de uma única cultura nacional. Até o século XVIII na Alemanha, Bildung assumiu um sentido pedagógico, designando um processo ao cabo do qual um indivíduo se torna a réplica de seu mentor, modelo exemplar ao qual ele acaba por se identificar. O pensamento alemão da época concebia a capacidade de aperfeiçoamento do homem como um instinto, de forma que a perfectibilidade do indivíduo particular se apresenta como um reflexo da marcha da humanidade. A ideia era que os indivíduos se modificam para melhor, assim como toda a humanidade. Formação, nesse sentido, se confundia com melhoria e aperfeiçoamento.

Na viagem do conceito, sofrendo toda sorte de influências e modificações, o Bildungsroman desemboca na França, com as designações de "romance de formação", "romance de aprendizagem" e "romance de educação" se tornando frequentes no discurso crítico em meados dos anos 1960. Esse paradigma crítico está diretamente relacionado com as inúmeras traduções feitas de romances de formação e obras teóricas alemães na França nessa época. Ainda hoje consta no Dicionário Littré o verbete "roman d'éducation", que se refere a um romance que representa a educação de um personagem fictício como exemplo de educação a ser seguido (PERNOT, 1994, p. 110). De toda forma, a crítica francesa, mesmo fazendo apropriações diversas do conceito, se concentra nas ideias comuns de estabelecimento de uma relação pedagógica entre o exemplo do indivíduo dado no romance e o leitor que nele deve se espelhar, do escopo moral do gênero e de uma conformação à ideologia

12. "à imagem de Toni Morrison nos Estados Unidos, a obra de Conceição Evaristo é a ilustração perfeita da maneira como a literatura pode ajudar a compreender melhor um país e a luta de todo um povo por seu reconhecimento..." [tradução das autoras] 
dominante (nesse sentido, o romance de formação seria um verdadeiro "romance de conformação"), já que o romance de formação existiria para dar um norte e um exemplo a jovens em processo educativo de formação ou aprendizagem.

Como se daria a recepção na França sob a égide da designação roman d'apprentissage para L'Histoire de Poncia? Antes, vejamos o que Pernot nos diz sobre a relação entre teoria da recepção, história literária e tradução, por ser imensamente elucidativo.

En posant que la signification de l'oeuvre littéraire repose sur la relation dialogique qu'elle instaure avec son public, la théorie de la réception exige de l'histoire littéraire qu'elle restitue les systèmes de référence (génériques, thématiques, narratologiques, idéologiques...) qui régissent sa lecture. Ces systèmes diffèrent d'un moment à l'autre mais aussi d'un espace à l'autre de l'histoire littéraire: toute traduction est phénomène de réception organisé par l'horizon d'attente qui structure à un moment donné l'espace culturel du public lisant dans la langue d'arrivée. (PERNOT, 1994, p. 105) ${ }^{13}$

Como a chave de leitura do romance de Evaristo como um romance de aprendizagem organiza o horizonte de expectativa e estrutura a recepção pelo público leitor na língua (e sistema) de chegada? Será que Ponciá representa um exemplo a ser seguido (tal como esperado de um romance de aprendizagem)? Será que esta é a preocupação principal da autora ao narrar essa história? Tal como o romance é estruturado, e principalmente segundo o seu fechamento, parece que o personagem principal coloca mais em evidência uma questão identitária (feminina, negra, minoritária) a ser problematizada do que propriamente um exemplo moral educativo. O público leitor francês que criar expectativas de encontrar um romance de aprendizagem, na linhagem dos romances de formação alemães do século XVIII, certamente vai se frustrar. L'Histoire de Poncia é bem outra coisa.

Em relação à segunda chave de leitura apresentada no material de divulgação disponibilizado pela editora, a inscrição do romance no catálogo da editora entre L'Enfant de la plantation et Je suis favela, os desdobramentos de leitura podem ser mais interessantes e produtivos. A editora Anacaona se dedica a traduzir e publicar muitos livros da dita "literatura marginal" brasileira, mas também clássicos da literatura denominada "regionalista" brasileira. O livro mencionado, Je suis favela, é uma coletânea de contos e novelas de autores variados, como Ferréz, Rodrigo

13. Afirmando que a significação da obra literária repousa sobre a relação dialógica que ela instaura com seu público, a teoria da recepção exige da história literária que ela restitua os sistemas de referência (genéricos, temáticos, narratológicos, ideológicos...) que regem sua leitura. Esses sistemas diferem não só de um momento para outro, mas também de um espaço para outro na história literária: toda tradução é fenômeno de recepção organizado pelo horizonte de expectativa que estrutura em certo momento o espaço cultural do público leitor na língua de chegada. [tradução das autoras] 
Ciríaco, João Anzanello Carrascoza, Marcelino Freire, Marçal Aquino, entre outros. Autores variados em seu background (alguns são oriundos de favelas e outros não), mas todos com o intuito de revelar e denunciar a realidade da violência urbana nas áreas periféricas, seja por sua ocupação territorial, seja por sua posição social desprestigiada. Já o outro livro mencionado, L'Enfant de la plantation, é a tradução de Menino de engenbo, de José Lins do Rego, lançado no Brasil em 1932 e traduzido pela primeira vez na França em 1953, pela editora Deux Rives (a nova tradução da Anacaona é de 2013). O primeiro livro, Je suis Favela, está incluído na seção "Romans Favela" e o segundo, L'Enfant de la plantation, na seção "Romans Nordeste", onde também se encontra L'Histoire de Poncia. De fato, o romance de Evaristo tem pontos de contato entre os dois extremos. Aproxima-se de José Lins do Rego pela temática da imigração, e da coletânea de escritores "marginais" pela temática da favela, da violência, da discriminação. Quando a editora diz que Poncia está entre os dois, ressalta pontos de contato sem igualar o romance a nenhum dos dois extremos, como se criasse uma gradação: nem tão canônico quanto o romance de Lins do Rego, nem tão marginal quanto a produção de ficção contemporânea brasileira, aparentada com o microconto, as narrativas fragmentadas e o foco na violência urbana das grandes metrópoles.

A terceira chave de leitura, de comparação entre Conceição Evaristo e Toni Morrison, se coaduna bem com a tradição comparatista de aproximar não iguais, na tentativa de facilitar e tornar mais palatável a recepção de um escritor novo e desconhecido pelo público leitor na língua/cultura alvo. Sem dúvida, as duas escritoras têm pontos de contato, mas também diferenças nítidas. $\mathrm{O}$ que as aproxima é a temática de gênero e da negritude, ambas são mulheres e negras, ambas tiveram que lutar contra preconceitos de todo tipo para empreender uma educação formal (chegando ao Doutorado), que não lhes era naturalmente destinada. O que as aparta seria basicamente o lugar que ocupam no sistema de língua/cultura de origem e de chegada. Toni Morrison é considerada uma das grandes escritoras vivas (ganhou o Prêmio Nobel de Literatura em 1993) não só nos Estados Unidos como em todo o mundo e Conceição Evaristo não é nem bem conhecida em seu país de origem, quiçá no mundo, embora venha aos poucos conquistando o seu espaço, como temos argumentado no presente artigo. Essa chave de leitura pode dar a crer ao leitor francês que Evaristo ocupa um lugar canônico semelhante ao de Morrison em seu país de origem, o que está longe de ser verdade.

O acima exposto nos leva a pensar na quarta e última chave de leitura apresentada pela editora, a de que o livro de Evaristo é leitura obrigatória para o vestibular no Brasil e de que foi muito vendido. Em primeiro lugar, o livro foi 
adotado por alguns concursos vestibulares no Brasil, mas não de forma geral, sendo que sua alta vendagem foi muito motivada por essa inclusão (e, portanto, lido principalmente por jovens que o leem apenas por essa razão específica), e não por ser um romance lido pelo grande público. É claro que a inclusão de um romance de uma escritora não canônica na lista de leituras obrigatórias de alguns vestibulares é algo muito relevante e que contribui para a divulgação e circulação da obra da autora. Porém, mais uma vez, a informação apresentada de forma generalizada dá a entender que o livro ocupa um lugar de mais destaque e mais canônico no sistema de língua/cultura de origem do que de fato ocorre. As considerações acima não querem dar a crer que Conceição Evaristo seja uma ilustre desconhecida no Brasil. Como aponta Eduardo de Assis Duarte em entrevista concedida em março de 2013,

Conceição, de todas as escritoras negras brasileiras, é a que mais visibilidade tem. Não estou dizendo que ela está sendo canonizada, não é isso, mas eu penso que ela conseguiu realmente furar um bloqueio muito forte. Sua obra não está publicada ainda por nenhuma grande editora, ela vem publicando em editoras menores, e vem tendo muito sucesso apesar disso, e dos problemas com a divulgação e a distribuição de seus livros, problemas característicos de editoras pequenas que não têm capital para investir na divulgação, propaganda, distribuição, coisas desse tipo. (VALENTE, 2013, p.137)

Contudo, o material de divulgação francês pode estar induzindo o leitor a tomar um caminho de recepção um pouco tendencioso. Tudo pode não passar de uma estratégia de marketing para fazer aumentar a vendagem do livro na França com a melhor das intenções talvez.

A recepção das obras literárias brasileiras na França possui uma história já longa, notadamente marcada pelo etnocentrismo. Um caso paradigmático nessa história foi a recepção de Mário de Andrade na França, discutida com profundidade por Teresa Dias Carneiro (CUNHA, 1999) em sua Dissertação de Mestrado, intitulada As obras de Mário de Andrade traduzidas na França: bistória, concepção e crítica. Até 1999, três obras de Andrade haviam sido traduzidas na França, Macunaíma (1979, revisada e reeditada em 1997), traduzido por Jacques Thiériot, Amar, verbo intransitivo (1995), traduzido por Maryvonne Lapouge-Pettorelli, e O turista aprendiz (1996), traduzido por Marie-Pierre Mazéas e Monique Le Moing.

Das três obras, a que chamou mais atenção da crítica foi, sem duvida, Macunaíma. Os artigos publicados na imprensa sobre essa obra em relação aos que tratam das demais são mais bem informados, mas não se pode dizer que sejam esclarecidos. Um pouco mais veladamente na reedição de 1997, os artigos continuam a bater na tecla do estereótipo, das ideias prontas e das frases feitas para caracterizar o Brasil, o brasileiro e a literatura brasileira. O exotismo é a tônica. Quanto à tradução, os nomes de Thiériot e Lapouge-Pettorelli, por serem tradutores conhecidos, são 
mencionados às vezes, em contraposição aos nomes de Mazéas e Le Moing, quase sempre esquecidos. Percebe-se que os artigos se repetem, levando a crer que os críticos basearam-se no press release, sem terem lido as traduções verdadeiramente. Um lugar comum repetido em alguns artigos é a comparação de Mário de Andrade com Rabelais, o que demonstra a opção preferencial na época pela aceitabilidade e por reiterar no repertório dos leitores as mesmas e batidas ideias. Da recepção das quatro publicações, a única que fugiu um pouco à regra foi a reedição de Macunaíma de 1997, por se tratar de uma edição crítica e mais completa, em que o próprio tradutor se encarregou de criar um aparato crítico substancial no paratexto da obra.

Percebeu-se uma postura, por parte dos críticos e editores franceses, de modo geral, de regulação da recepção pelo viés da redução ao já conhecido, e do apelo ao exótico invocado pela selva, a flora e a fauna brasileiras. Mesmo a recepção de um romance urbano como Amar, verbo intransitivo, ambientado em uma grande cidade, não foge aos chavões repetidos ad nauseam que reduzem "o outro" ao mesmo.

\section{CONSIDERAÇÕES FINAIS}

Por tudo que discutimos acima, a recepção na França do romance de Evaristo pode estar reproduzindo características bem conhecidas na recepção francesa da literatura brasileira traduzida. No estudo da recepção das obras de Mário de Andrade traduzidas na França (CUNHA, 1999), percebeu-se que lá há uma tendência marcante de circunscrever e regular a recepção à tradução de literatura brasileira (com enfoques que muitas vezes ressaltam o exotismo, a liberalidade de costumes e o devaneio) pelo viés do auto-referenciamento ou da auto-definição cultural (como classificar o romance de Evaristo como romance de aprendizagem, e Macunaíma de Mário de Andrade como roman de la jungle), ou da aproximação com o que é conhecido e compreendido (comparação de Evaristo com Morrison e de Andrade com Rabelais). As chaves de leitura redutoras, depreendidas do material de recepção de L'Histoire de Poncia podem se repetir em outros contextos, de obras de outros autores brasileiros, como Mário de Andrade, constituindose verdadeiro lugar comum. Da repetição automática de ideias feitas ou atitudes reducionistas, nem mesmo a editora Anacaona escapa na regulação da recepção, mesmo proporcionando a possibilidade louvável de fazer contato do leitor francês com muito da produção literária contemporânea brasileira. Novidades em relação ao estudo de 1999 aparecem (a segunda chave de leitura, por exemplo), mas a tendência do auto-referenciamento cultural pela recepção francesa ainda se faz muito presente. O exótico do final da década de 1990, representado pela floresta, 
pelo sonho e pelo devanio, parece se substituir, em 2015, pelo exótico da favela e da periferia. A substituição de temas e autores não muda o essencial nesses quase 20 anos passados entre o estudo das obras traduzidas de Mário de Andrade e de Conceição Evaristo: uma recepção em grande parte reducionista e equivocada. A literatura brasileira na França vem sendo, de modo geral, recebida como periférica, principalmente por parte dos críticos, que insistem em lê-la tendo como pano de fundo referências culturais francesas ou europeias ou, no extremo oposto, referências culturais vertiginosamente distanciadas dessa cultura. O diálogo a ser estabelecido fica difícil, pois ou os interlocutores são vistos como assimilados ou tão distanciados que não há possibilidade de entendimento. Porém, isso parece estar mudando, mesmo que lentamente.

Por fim, pelas resenhas e pelos fragmentos de matérias jornalísticas apresentados e comentados ao longo do presente estudo, acreditamos estar claro que a acolhida de L'Histoire de Poncia vem sendo bastante positiva na França até o momento, e que a escritora Conceição Evaristo, assim como a editora Anacaona, tem recebido muitos elogios pelo romance publicado nesse ambiente. Assim, embora Evaristo não seja uma escritora canônica e sua obra tenha certa dificuldade de circulação nos três países em que foi publicada (Brasil, Estados Unidos e França), até mesmo por ter sido publicada por editoras pequenas (Mazza, Host e Anacaona, respectivamente), a escritora vem sendo lida e estudada, embora em contextos ainda restritos, tornando-se referência no que diz respeito aos estudos de questões relacionadas a gênero e, principlamente, a negritude em nosso país, indo além das barreiras nacionais através de suas traduções para as línguas inglesa e francesa.

\section{REFERÊNCIAS BIBLIOGRÁFICAS}

ANACAONA, P. (2014). Conexões Itaú Cultural. Disponível em: http://novo.itaucultural. org.br/canal-video/paula-anacaona-conexoes-2014/. Acesso em: 25 mai. 2015.

ARAÚJO, B. (2011). Conceição Evaristo: literatura e consciência negra. Blogueiras feministas: de olho na web e no mundo. Publicado em: 22/11/2011. Disponível em: http://blogueirasfeministas.com/2011/11/conceicao-evaristo/. Acesso em: 04 set. 2015.

ARRUDA, A. A. (2007). Ponciá Vicêncio, de Conceição Evaristo: um Bildungsroman feminino e negro. Dissertação de Mestrado em Teoria da Literatura. Instituto de Letras, Universidade Federal de Minas Gerais, Belo Horizonte. 
CASARIN, R. (2015). Editora francesa aposta na literatura marginal brasileira. Blog Página Cinco. Publicado em: 02/04/2015. Disponível em: http://paginacinco. blogosfera.uol.com.br/2015/04/02/editora-francesa-aposta-na-literatura-marginalbrasileira/\#comentarios. Acesso em: 25 de ago. de 2015.

CUNHA, T. D. C. As obras de Mário de Andrade traduzidas na França: bistória, concepção e crítica. 1999. 293p. Dissertação (Mestrado em Ciência da Literatura/Literatura Comparada) - Faculdade de Letras. Universidade Federal do Rio de Janeiro (UFRJ). Disponível em https://docs.wixstatic.com/ugd/086022_5466677141494fde9621e787a19b31 7e.pdf.

EVARISTO, C. (2003). Ponciá Vicêncio. Belo Horizonte: Mazza.

EVARISTO, C. (2003). Ponciá Vicêncio. 2 ed. Belo Horizonte: Mazza, 2006.

EVARISTO, C. (2003). Ponciá Vicencio, trad. Paloma Martinez-Cruz. Texas: HostPublications, 2007.

EVARISTO, C. (2003). L'bistoire de Poncia, trad. Paula Anacaona e Patrick Louis. Paris: Éditions Anacaona, 2015.

GUEDES, D. (2015). Conheça a Anacaona, a editora francesa especializada em literatura brasileira. Jornal do Commercio online. Cultura. Publicado em 10/05/2015. Disponível em: http://jconline.ne10.uol.com.br/canal/cultura/literatura/noticia/2015/0 5/10/conheca-a-anacaona-a-editora-francesa-especializada-em-literatura-brasileira-180437. php. Acesso em: 30 ago. 2015.

NETTO, A. (2015). Sucesso do Brasil no Salão do Livro de Paris expõe gargalo das traduções. O Estado de São Paulo online. Publicado em 23/03/2015. Disponível em: http://cultura.estadao.com.br/noticias/literatura, sucesso-do-brasil-no-salao-dolivro-de-paris-expoe-gargalo-das-traducoes,1655737. Acesso em: 12 mai. 2015.

NEVES, L. (2015). Negra em Salão do Livro causa furor, diz autora brasileira. Folba de São Paulo. Publicado em 23/03/2015. Disponível em: http://www1.folha.uol.com. br/ilustrada/2015/03/1606652-negra-em-salao-do-livro-causa-furor-diz-autorabrasileira.shtml. Acesso em: 30 mar. 2015.

PERNOT, D. (1992) Du 'Bildungroman' au roman d'éducation: un malentendu créateur. Romantisme, $\mathrm{n}^{\circ} 76$, II, p. 105-119. Disponível em: http://www.persee.fr/doc/ roman_0048-8593_1992_num_22_76_6034. Acesso em: 04 out. 2015. 
SILVA, Luciana de Mesquita; VALENTE, Marcela Iochem. Narrativas no espelho: algumas considerações sobre a recepção de $\mathrm{O}$ olho mais azul, de Toni Morrison, e Ponciá Vicencio, de Conceição Evaristo. Caderno de Letras (UFPEL), v. 23, p. 109-138, 2014.

VALENTE, Marcela Iochem. A tradução e a construção de imagens culturais: Ponciá Vicêncio, de Conceição Evaristo, e sua tradução para o inglês. 2013. 162p. Tese (Doutorado em Estudos Letras - da Linguagem) - Departamento de Letras. Pontifícia Universidade Católica do Rio de Janeiro. 